\title{
Predictive Analysis Using Chemical-Gene Interaction Networks Consistent with Observed Endocrine Activity and Mutagenicity of U.S. Streams
}

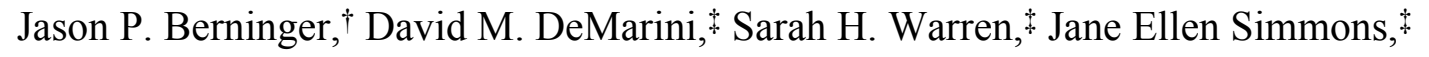 \\ Vickie S. Wilson, $₫$ Justin M. Conley, $₫$ Mikayla D. Armstrong, ${ }^{\S}$ \\ Luke R. Iwanowicz, ${ }^{\complement}$ Dana W. Kolpin, ${ }^{\|}$Kathryn M. Kuivila, ${ }^{\perp}$ Timothy J. Reilly, ${ }^{\#}$ Kristin M. \\ Romanok, ${ }^{\#}$ Daniel L. Villeneuve, ${ }^{\nabla}$ and Paul M. Bradley*,
}

†Columbia Environmental Research Center, U.S. Geological Survey, Columbia, Missouri 65201, United States

National Health and Environmental Effects Research Laboratory, U.S. Environmental Protection Agency, Research Triangle Park, North Carolina 27711, United States

$\S$ Department of Environmental Science and Engineering, University of North Carolina, Chapel Hill, North Carolina 27599, United States

'Leetown Science Center, U.S. Geological Survey, Kearneysville, West Virginia 25430, United States

$\|$ Central Midwest Water Science Center, U.S. Geological Survey, Iowa City, Iowa 52240, United States

${ }^{\perp}$ Oregon Water Science Center, U.S. Geological Survey, Portland, Oregon 97201, United States

\#New Jersey Water Science Center, U.S. Geological Survey, Lawrenceville, New Jersey 08648, United States

${ }^{\nabla}$ National Health and Environmental Effects Research Laboratory, U.S. Environmental Protection Agency, Duluth, Minnesota 55804, United States

${ }^{\circ}$ South Atlantic Water Science Center, U.S. Geological Survey, Columbia, South Carolina

29210, United States

*Corresponding author: Phone 803-727-9046; e-mail: pbradley@usgs.gov.

\section{Figures}


Figure S1. Linear regressions of mutagenicity dose-response curves of mutagenic samples; data from Table S1. Non-mutagenic samples are not shown.

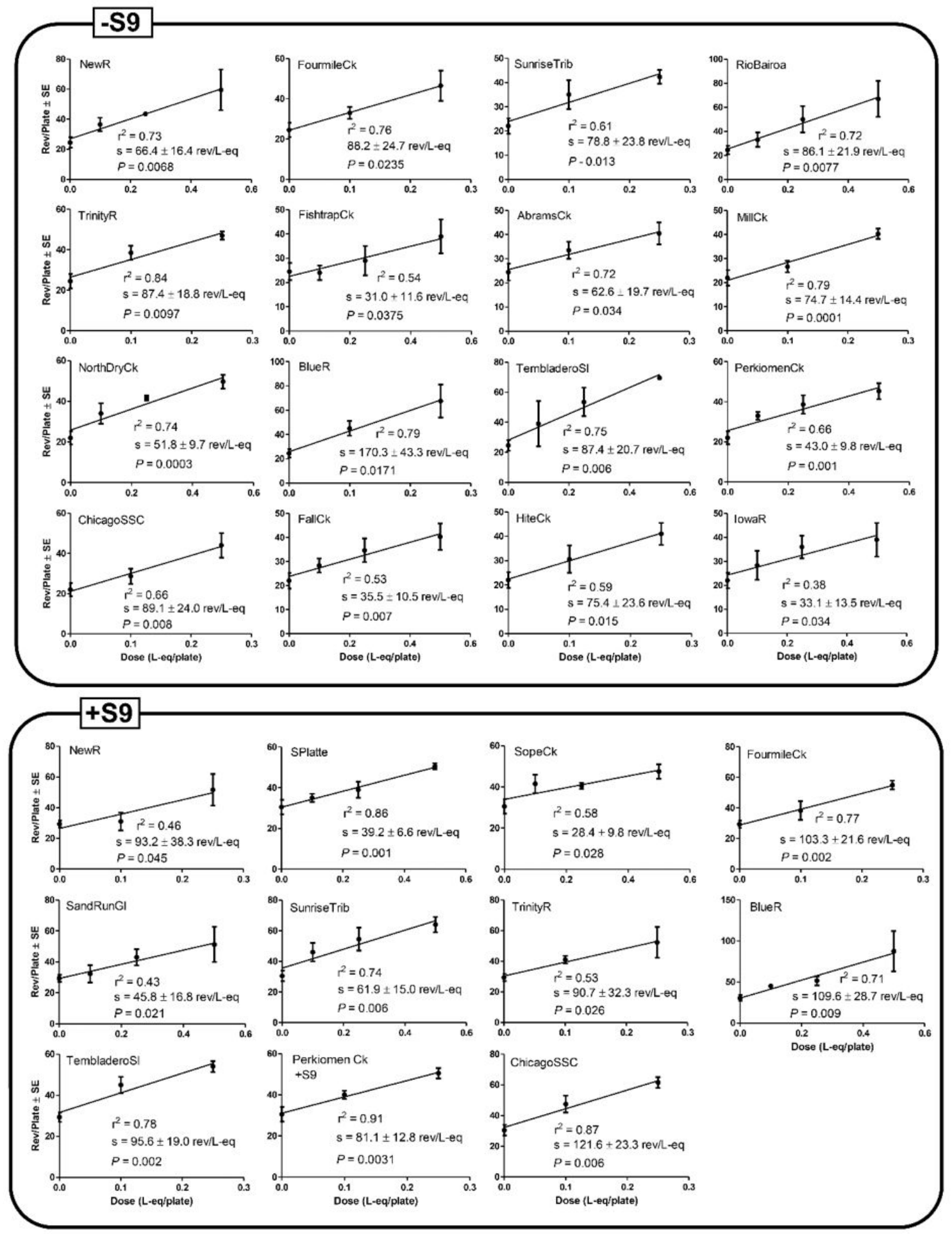


Figure S2. Site clusters by pCGA (gene interaction) count. Clusters based on all 25,479 genes, top 250 shown.

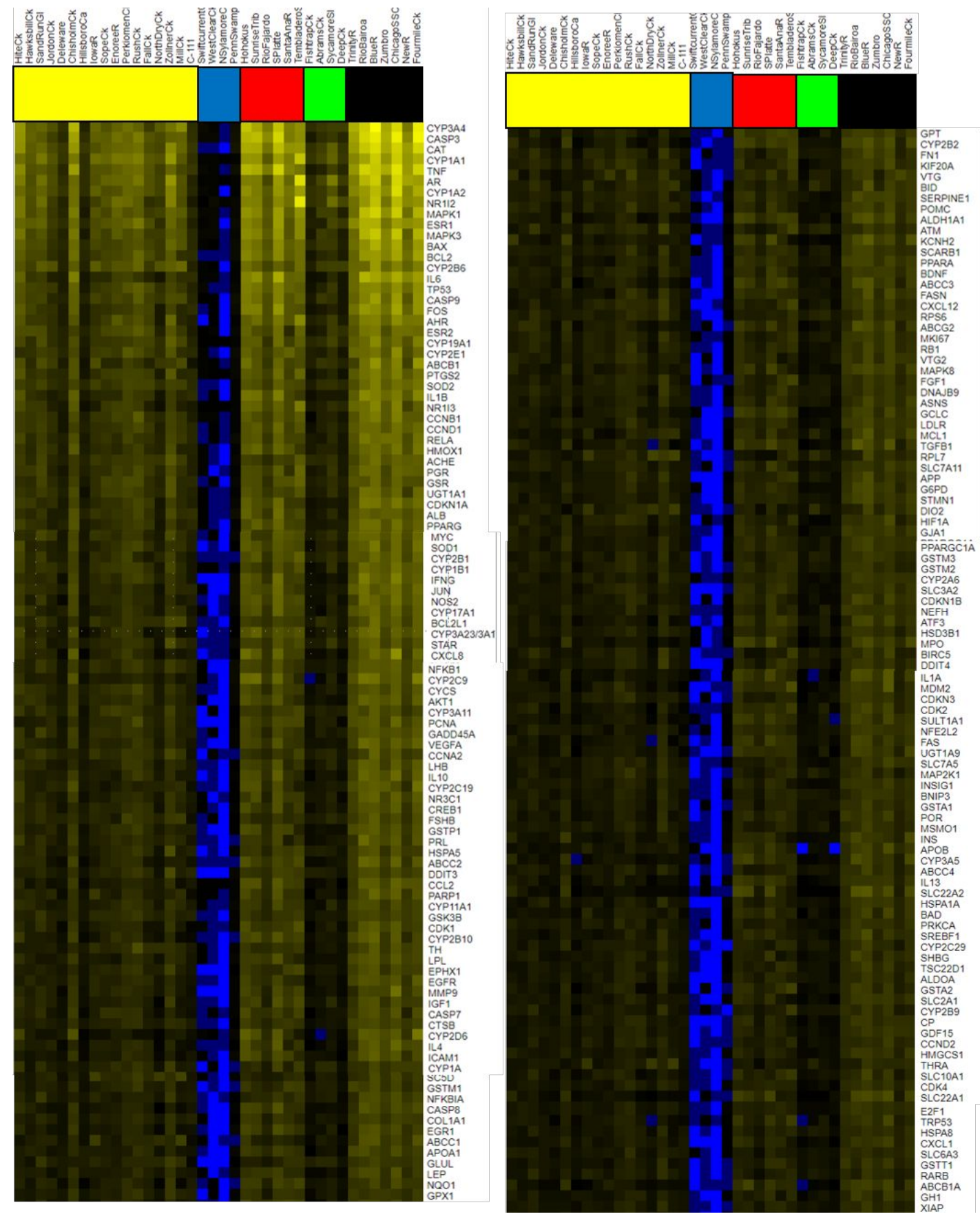


Figure S3. pCGA by concentrations.

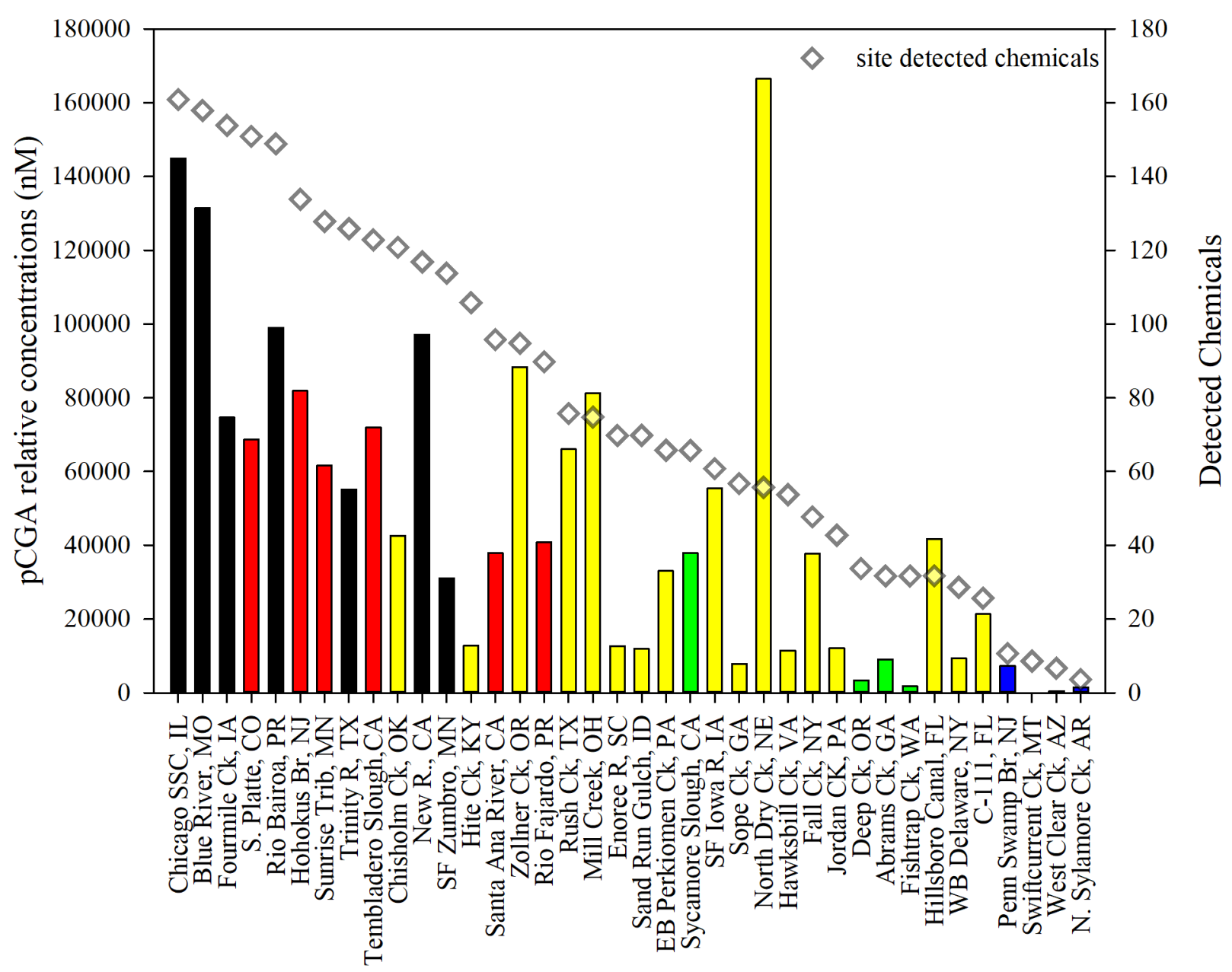


Figure S4. Sites clustered by pPLA (pathway interaction) counts. Clusters based on all 1861 pathways (top 250 shown).
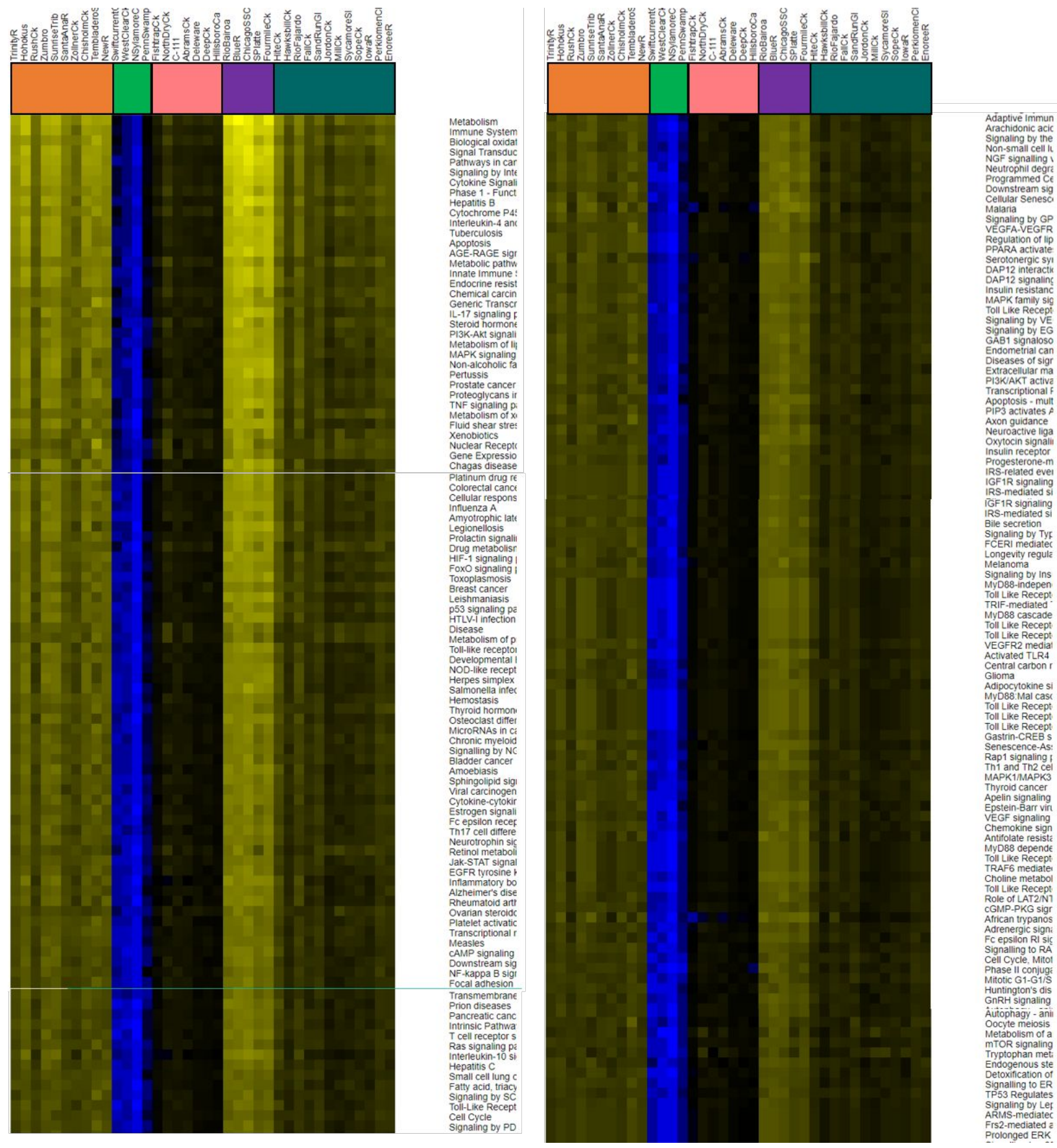
Figure S5. pPLA by count.

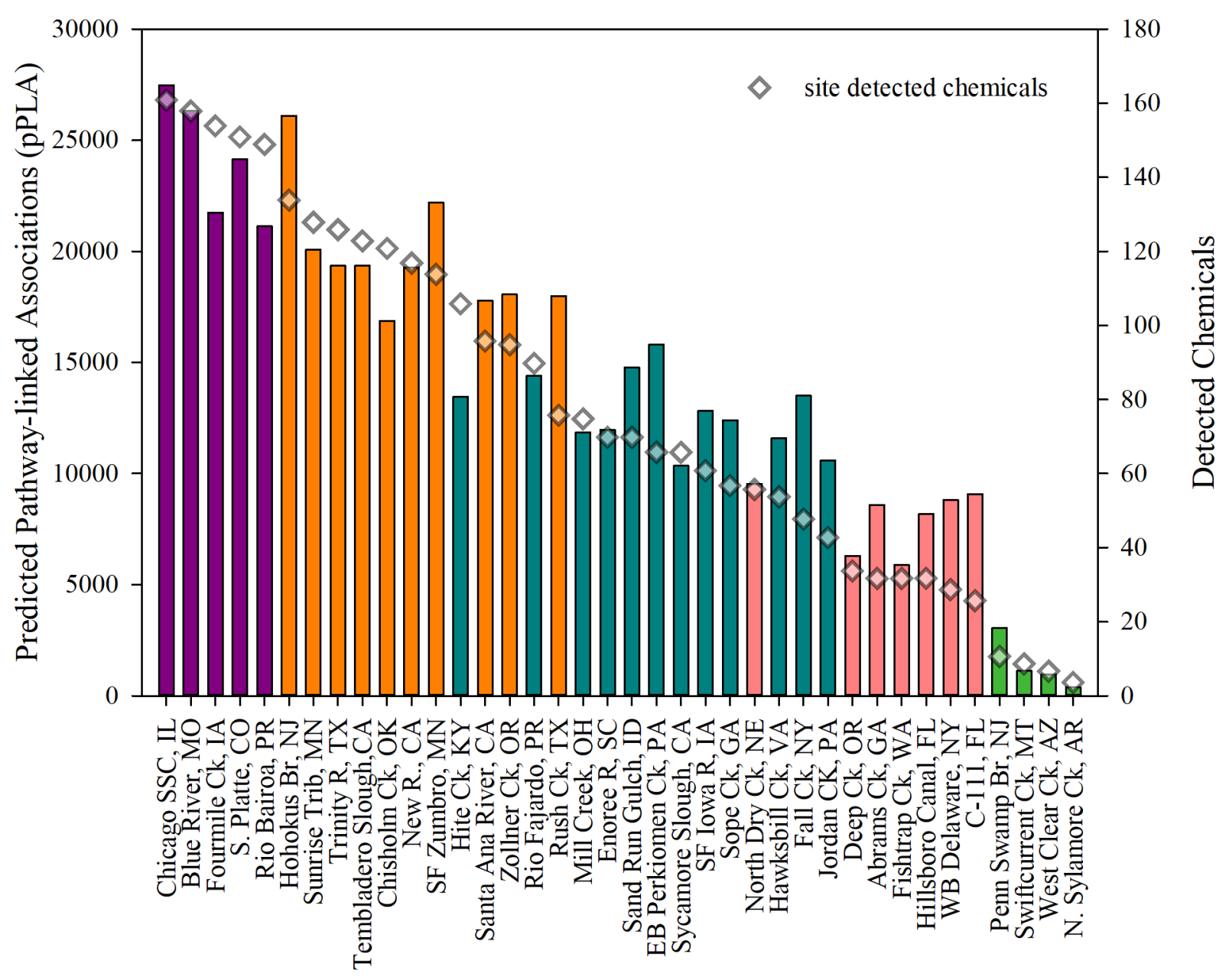


Figure S6. pPLA by relative concentration.

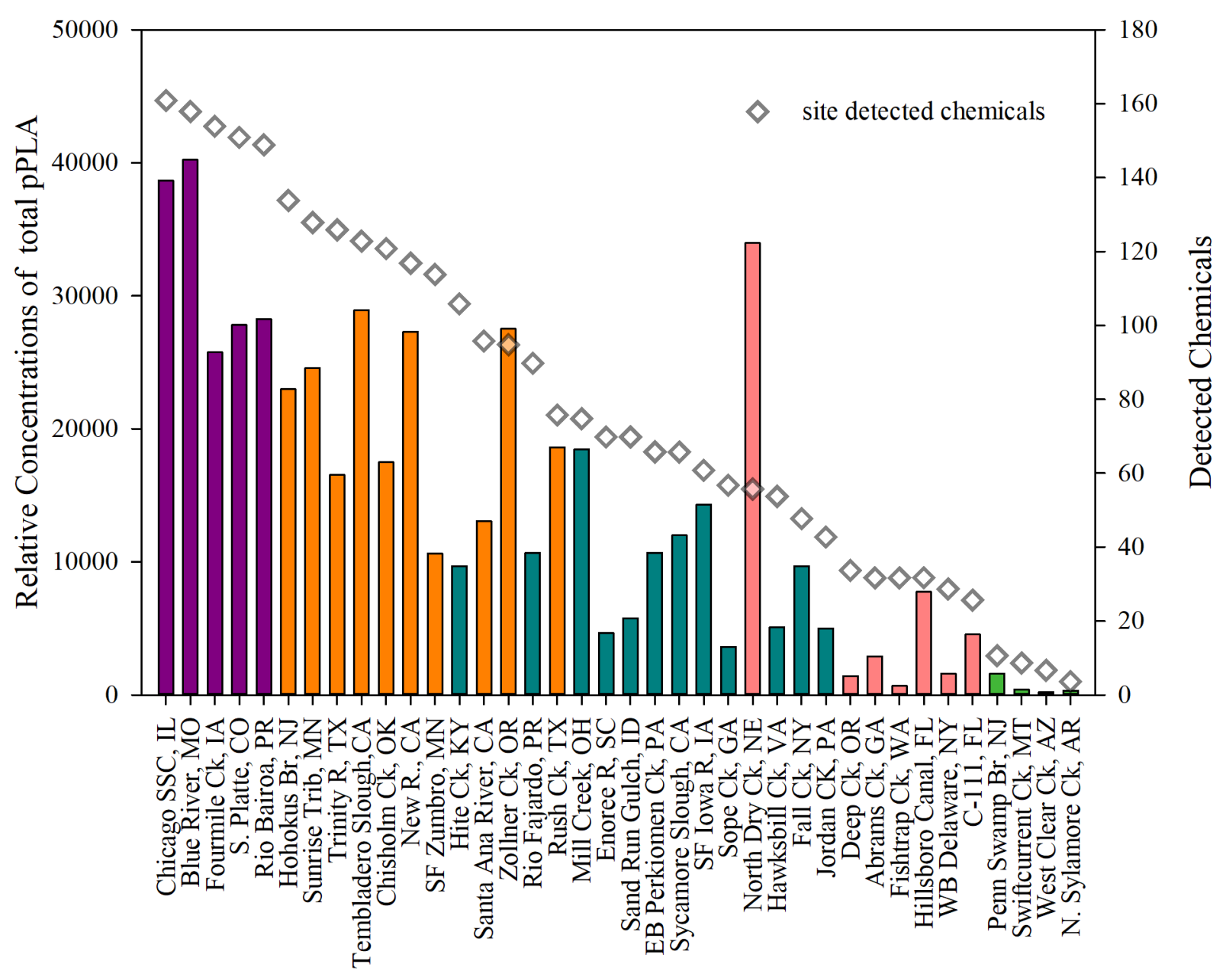


Figure S7. Chemical interaction with pathways at five example sites to show differences in potential response between degree of pathway interaction.

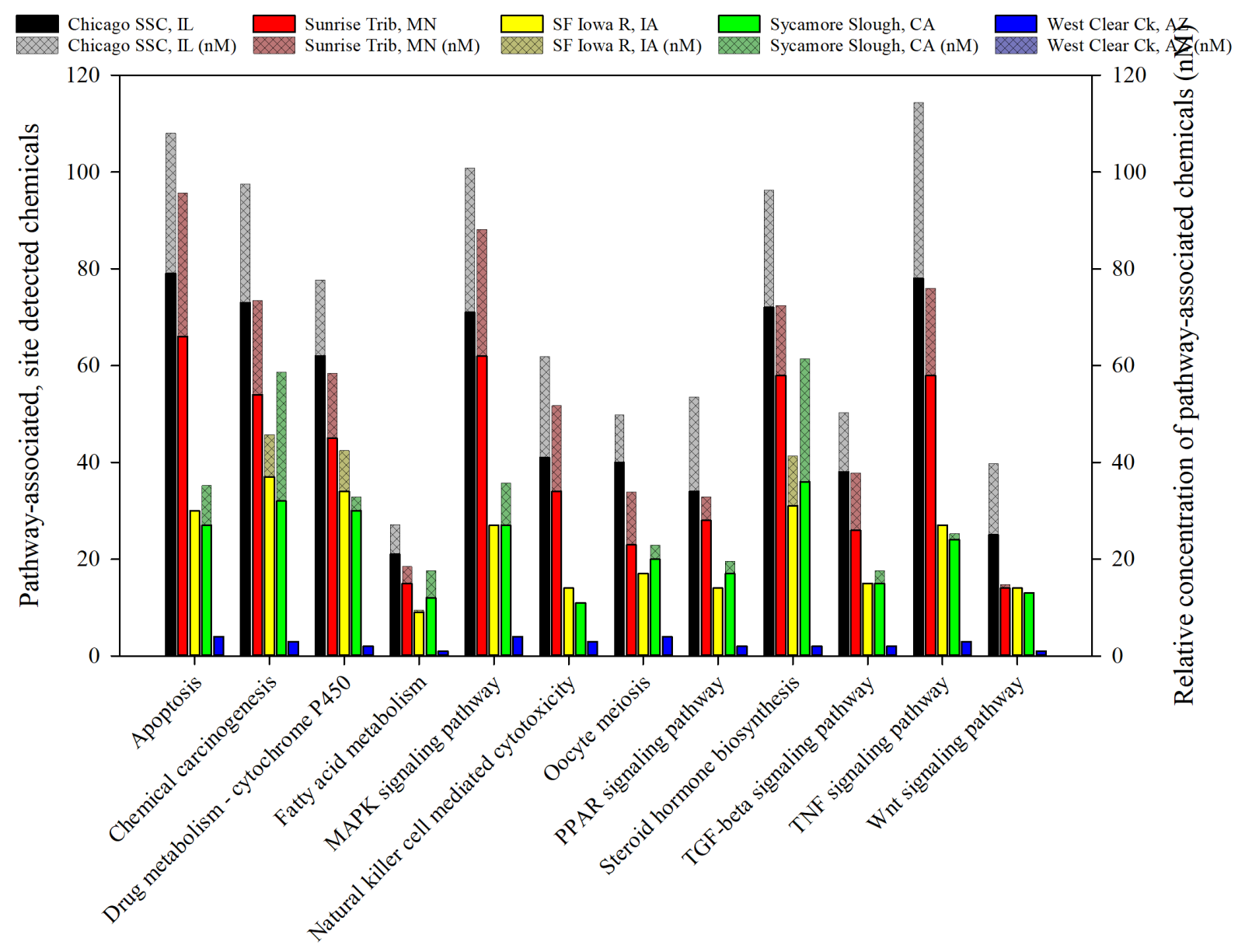

Genes 
Figure S8 . Pie charts represent site-specific pathway interactions (for the example sites) grouped according to 9 different broad biological response groups (BBRGs). Each pie was scaled relative to the ChicagoSSC site to represent the maximum count of chemicals interacting with pathways designated in each BBRG. One site, WestClear was not true to scale as actual scaled pie was not readable.

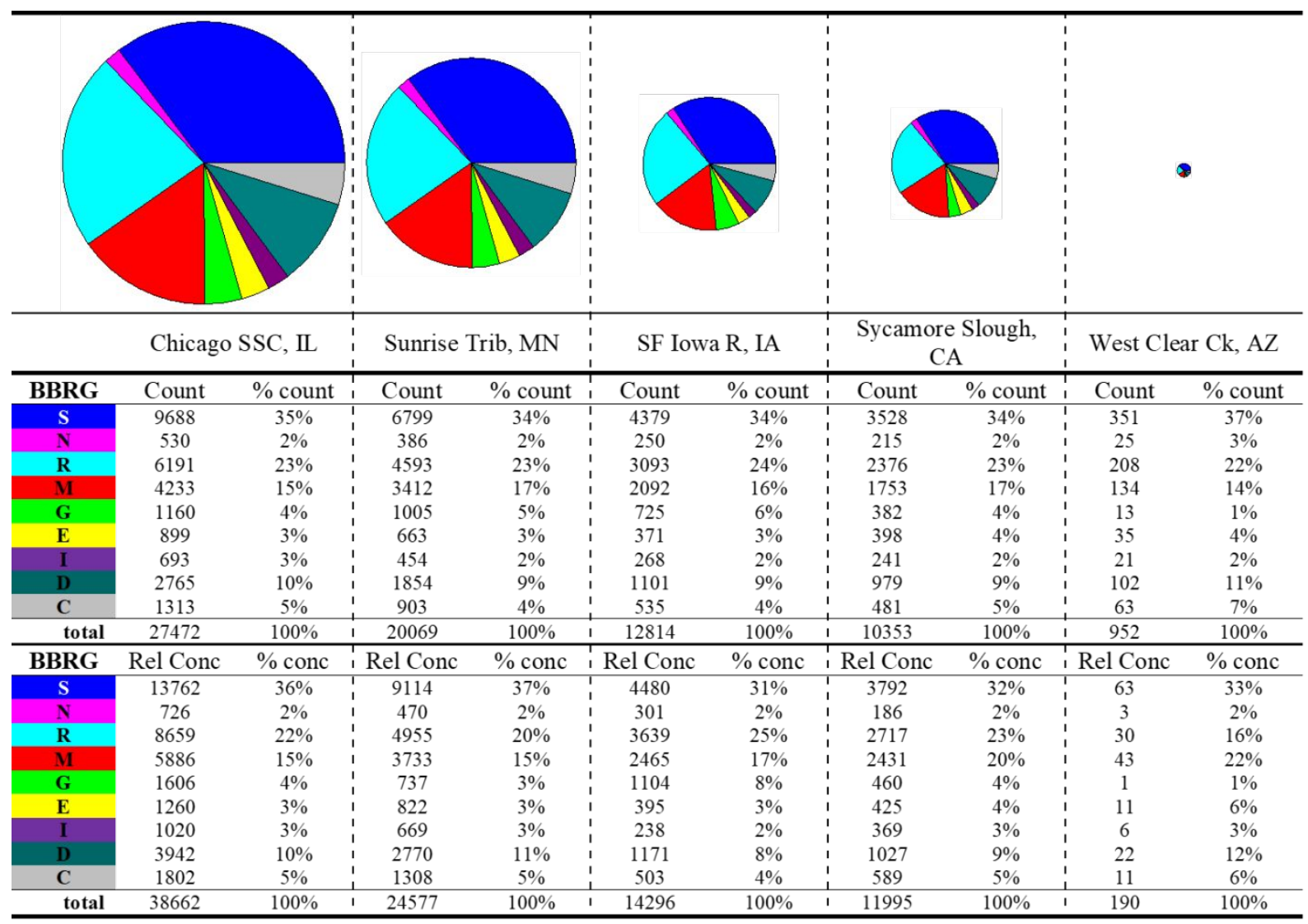


Figure S9. Comparison of observed mutagenicity and predicted cancer-pathway chemicals in surface-water samples.

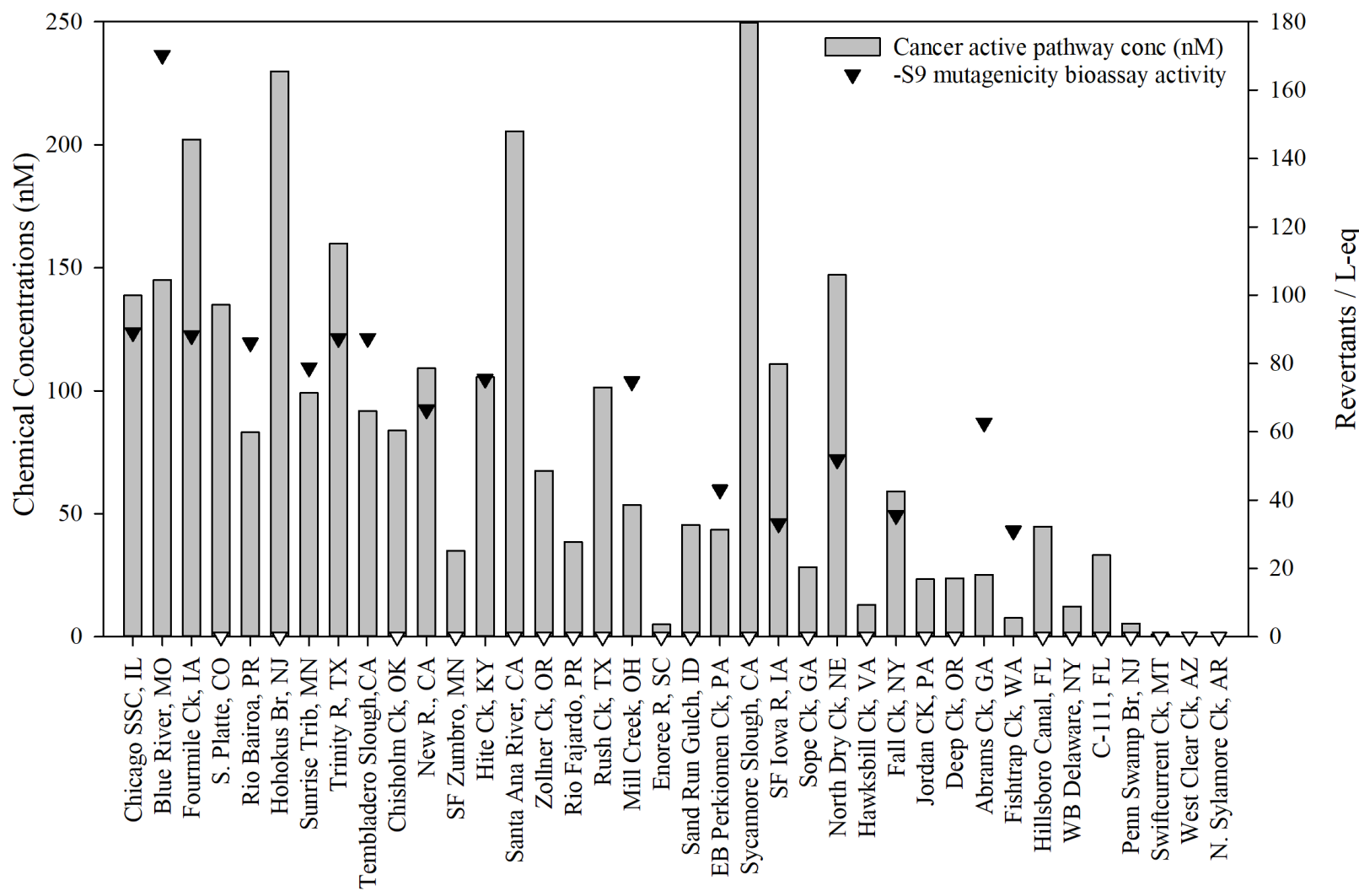

Sites 